\title{
CONSERVAÇÃO DE TECIDOS SOMÁTICOS DE CATETOS (Pecari tajacu LINNAEUS, 1758) SUBMETIDO A DIFERENTES CONDIÇÕES DE ARMAZENAMENTO
}

M. B. SILVA ${ }^{1}$, L. B. DE QUEIROZ NETA ${ }^{2}$, L. R. M. DE OLIVEIRA ${ }^{3}$, M. B. DO NASCIMENTO ${ }^{4}$, L. V. C. DE AQUINO ${ }^{5}$, A. A. BORGES ${ }^{6}$, M. V. DE O. SANTOS ${ }^{7}$, A. F. PEREIRA ${ }^{8}$

Universidade Federal Rural do Semi-Árido

ORCID ID: http://orcid.org/0000-0001-5745-32791

brbarasilva46@yahoo.com ${ }^{1}$

Submetido 07/04/2020 - Aceito 18/12/2020

DOI: $10.15628 /$ holos.2020.9862

\section{RESUMO}

O objetivo foi avaliar a influência da conservação [refrigeração a $5^{\circ} \mathrm{C}$ e vitrificação] sobre tecidos somáticos de catetos. $O$ experimento foi dividido em duas etapas. Na primeira etapa, fragmentos foram refrigerados por 24 (R-24) e 48 h (R-48) e comparados com amostras não refrigeradas (C). Na segunda etapa, fragmentos foram refrigerados por 24 (RV-24) e 48 h (RV-48) seguidos da vitrificação, e comparados com fragmentos apenas vitrificados (V). Na primeira etapa, embora a espessura da epiderme não tenha sido afetada pela refrigeração por $48 \mathrm{~h}$, a espessura da derme foi reduzida tanto no período de $24 \mathrm{~h}$ quanto de $48 \mathrm{~h}$. Além disso, enquanto uma redução de fibroblastos dérmicos foi apenas evidenciada no grupo R-48, o aumento de halos perinucleares da epiderme foi observado em todos os grupos refrigerados. $\mathrm{Na}$ segunda etapa, tanto a espessura da epiderme, quanto da derme e total foram afetadas pela vitrificação após a refrigeração por 48 h. Além disso, enquanto uma redução de fibroblastos dérmicos foi apenas evidenciada no grupo RV-48, o aumento de halos perinucleares da epiderme foi observado em todos os grupos vitrificados. Assim, independente do período de armazenamento, a refrigeração afetou a qualidade dos tecidos somáticos de catetos, sendo esses efeitos acentuados quando os fragmentos foram refrigerados por $48 \mathrm{~h}$ e vitrificados. Portanto, sugere-se, quando necessário, o período de 24 $\mathrm{h}$ de refrigeração para amostras somáticas derivadas de catetos que irão ainda ser vitrificadas.

PALAVRAS-CHAVE: mamíferos silvestres, criopreservação tecidual, refrigeração de amostras somáticas.

\section{CONSERVATION OF SOMATIC TISSUES FROM COLLARED PECCARIES (Pecari tajacu LINNAEUS, 1758) SUBMITTED TO DIFFERENT STORAGE CONDITIONS}

\begin{abstract}
The aim was to evaluate the influence of conservation [refrigeration at $5^{\circ} \mathrm{C}$ and vitrification] on somatic tissues derived from collared peccaries. The experiment was divided into two stages. In the first step, fragments were refrigerated for $24(\mathrm{R}-24)$ and $48 \mathrm{~h}(\mathrm{R}-48)$ and compared with non-refrigerated samples (C). In the second step, fragments were refrigerated for 24 (RV-24) and $48 \mathrm{~h}$ (RV48) followed by vitrification and compared with vitrified fragments (V). In the first step, although the thickness of the epidermis was not affected by refrigeration for $48 \mathrm{~h}$, the thickness of the dermis was reduced in both the $24 \mathrm{~h}$ and $48 \mathrm{~h}$ periods. Moreover, while a reduction in dermal fibroblasts was only evident in the group R-48, the increase in perinuclear halos of the epidermis was
\end{abstract}

observed in all groups. In the second step, both the thickness of the epidermis, the dermis and the total were affected by vitrification after refrigeration for $48 \mathrm{~h}$. Additionally, while a reduction in dermal fibroblasts was only evident in the group RV-48, an increase in perinuclear halos of the epidermis was observed in all vitrified groups. Thus, regardless of the storage period, refrigeration affected the quality of the somatic tissues of collared peccaries, these effects being accentuated when the fragments were refrigerated for $48 \mathrm{~h}$ and vitrified. Therefore, it is suggested, when necessary, the $24 \mathrm{~h}$ refrigeration period for somatic samples derived from collared peccaries that will still be vitrified.

KEYWORDS: wild mammals, tissue cryopreservation, refrigeration of somatic samples. 


\section{INTRODUÇÃO}

Os catetos, mamíferos da família Tayassuidae, pertencentes à ordem Artiodátila, são exclusivos na América e estão amplamente distribuídos desde o sul dos Estados Unidos até o norte da Argentina, sendo encontrados em todo o território brasileiro e ocupando os mais diversos ambientes (Minervino et al., 2014). Atualmente, segundo a União Internacional para a Conservação da Natureza (IUCN, 2020), sua população é estável, estando a espécie classificada como menos preocupante. Contudo, em virtude das taxas contínuas de destruição de habitats (Desbiez et al., 2012), a crescente caça predatória e por estarem em algumas regiões considerados como praga agrícola (Mayor et al., 2007), o status populacional requer monitoramento.

Nesse sentido, a otimização de protocolos relacionados à conservação de material genético, visando seu posterior uso em biotecnologias, torna-se uma ferramenta interessante para a manutenção desta espécie. Nesse cenário, estudos relacionados à conservação de tecido ovariano (Lima et al., 2014), testicular (Silva et al., 2019) e somático (Borges et al., 2017) já foram desenvolvidos em catetos. Especificamente quanto a este último exemplo, amostras somáticas têm se tornando uma alternativa importante para a conservação da biodiversidade, uma vez que esse tipo de amostra permitem uma maior representação populacional da espécie de interesse (Pereira et al., 2019) e as células oriundas desses tecidos podem ser empregadas na clonagem por transferência nuclear de células somáticas (Sharma et al., 2018).

Assim, como técnicas de conservação de tecidos somáticos usadas em mamíferos silvestres, têm-se a criopreservação por congelação lenta (Caamaño et al., 2008), por vitrificação (Borges et al., 2017) e a refrigeração (Queiroz Neta et al., 2018). Esta última tem sido empregada especialmente para o transporte ou conservação em curto prazo de tecidos somáticos de indivíduos localizados em regiões de difícil acesso ou distantes dos laboratórios especializados (Tovar et al., 2008). Já a vitrificação tem sido o método de escolha quando comparado a congelação lenta para a conservação em longo período de tempo (Silvestre et al., 2003).

Embora tanto a refrigeração quanto à vitrificação possam ser empregadas na conservação de tecidos somáticos de mamíferos silvestres, é interessante conhecer o efeito dessas ferramentas sobre a qualidade e a viabilidade celular, especialmente quanto à influência da refrigeração sobre a vitrificação de tecidos somáticos (Silvestre et al., 2004). Nos estudos realizados por Silvestre et al. (2003) em mamíferos domésticos (leporinos e suínos), os autores observaram que a conservação a $4^{\circ} \mathrm{C}$ de fragmentos da pele resultou em um aumento no tempo de manipulação da pele desde a colheita até o processamento no laboratório, minimizando os efeitos negativos, como alterações patológicas e necrose tecidual.

Além disso, quando o transporte de amostras somáticas é realizado a $35^{\circ} \mathrm{C}$ ou a temperaturas superiores a $20^{\circ} \mathrm{C}$, tais condições podem interferir na viabilidade tecidual até o momento da criopreservação (Silvestre et al., 2003). Isso porque tais temperaturas podem expor as amostras a contaminações microbiológicas, acelerando a morte das células (Silvestre et al., 2002). 
Nesse sentido, faz-se necessário o estabelecimento de pelo menos dois períodos de tempo, dentro de até dois dias ( $48 \mathrm{~h}$ ), na tentativa de mimetizar as condições em que a colheita de amostras somáticas seja de indivíduos distantes do laboratório em questão, seguido da vitrificação. Portanto, o objetivo do presente estudo foi avaliar a influência da conservação [refrigeração a $5^{\circ} \mathrm{C}$ por $24 \mathrm{~h}$ ou $48 \mathrm{~h}$ e vitrificação] sobre tecidos somáticos derivados de catetos.

\section{METODOLOGIA}

O presente estudo foi aprovado pelo Comitê de Ética de Uso de Animais da Universidade Federal Rural do Semi-Árido (CEUA/UFERSA, no. 23091.001072/2015-92), bem como pelo Instituto Chico Mendes de Conservação da Biodiversidade (ICMBio, no. 48633-2). O desenho experimental foi dividido em duas etapas. A primeira etapa consistiu na avaliação da refrigeração a $5^{\circ} \mathrm{C}$ na conservação de tecidos somáticos, comparando os seguintes grupos: i) fragmentos não refrigerados $\left(25-26^{\circ} \mathrm{C}\right.$, controle), ii) fragmentos refrigerados a $5^{\circ} \mathrm{C}$ por $24 \mathrm{~h}(\mathrm{R}-24)$ e iii) fragmentos refrigerados a $5^{\circ} \mathrm{C}$ por $48 \mathrm{~h}$ (R-48). A segunda etapa consistiu na avaliação da refrigeração a $5^{\circ} \mathrm{C}$ sobre a vitrificação de tecidos somáticos, comparando os seguintes grupos: i) fragmentos apenas vitrificados (vitrificação) (V), ii) fragmentos refrigerados a $5^{\circ} \mathrm{C}$ por $24 \mathrm{~h}$ e vitrificados (RV-24) e iii) fragmentos refrigerados a $5^{\circ} \mathrm{C}$ por $48 \mathrm{~h}$ e vitrificados (RV-48). Para os grupos das duas etapas, análises foram realizadas nos fragmentos utilizando a coloração de hematoxilina-eosina.

Para tanto, um total de quatro animais (um animal = uma repetição) com idade entre três a cinco meses, do gênero masculino, provenientes do CEMAS/UFERSA (IBAMA, no.12.492-0004) foi utilizado. No CEMAS, a identificação dos catetos é realizada com cortes na região apical do pavilhão auricular $\left(1-2 \mathrm{~cm}^{2}\right)$ com o auxílio de um alicate e esses fragmentos foram usados nos experimentos. Após a biópsia de pele, as amostras foram lavadas com álcool a 70\% e transportadas imediatamente ao laboratório a $5^{\circ} \mathrm{C}$. No laboratório e sob fluxo laminar, as amostras foram tricotomizadas, fragmentadas em $9,0 \mathrm{~mm}^{3}$ e divididas aleatoriamente entre as etapas experimentais. Cada grupo conteve fragmentos de todos os animais, sendo quatro fragmentos por animal, totalizando quatro animais e 16 fragmentos em cada grupo.

Para a refrigeração, os fragmentos foram armazenados na ausência de meio a $5^{\circ} \mathrm{C}$ em tubos cônicos de $15 \mathrm{~mL}$, previamente identificados de acordo com cada animal e período de armazenamento. A temperatura do refrigerador $\left(5^{\circ} \mathrm{C}\right.$ a $\left.5,4^{\circ} \mathrm{C}\right)$ foi verificada utilizando termômetro ambiental, conforme realizado por Okonkwo e Singh (2014).

Para a criopreservação das amostras somáticas foi realizada a vitrificação em superfície sólida, conforme Borges et al. (2017), tendo como solução de vitrificação aquela estabelecida por Borges et al. (2018): meio essencial mínimo modificado por Dulbecco (DMEM) contendo 10\% de soro fetal bovino (SFB), 3,0 M de etilenoglicol (EG) e 0,25 M de sacarose. Após o período de refrigeração, de acordo com o desenho experimental, os fragmentos foram expostos a 1,8 $\mathrm{mL}$ de solução de vitrificação por 5 min e, em seguida, secos em papel absorvente. Posteriormente, os fragmentos foram colocados individualmente sobre uma superfície cúbica de metal parcialmente 
submersa em nitrogênio líquido, transferidos em seguida para criotubos e armazenados em nitrogênio líquido. Após duas semanas, os criotubos foram mantidos por $1 \mathrm{~min}$ a $25^{\circ} \mathrm{Ce}$, em seguida, imersos em banho-maria a $37^{\circ} \mathrm{C}$. Para remoção do crioprotetor, os fragmentos foram lavados três vezes por 5 min em DMEM acrescido de 10\% de SFB e sacarose em concentrações decrescentes $(0,50 ; 0,25$ e $0,0 \mathrm{M})$.

Para o processamento histológico, todos os procedimentos foram realizados conforme descrito por Borges et al. (2017) com modificações. Para tanto, os fragmentos foram imediatamente após processamento fixados em paraformaldeído a $4 \%$, desidratados por sucessivas lavagens com soluções de etanol em concentrações crescentes e diafanizados em xilol. Posteriormente, foram inclusos em parafina, seccionados em cortes seriados de 7,0 $\mu \mathrm{m}$ e corados com hematoxilina e eosina. A caracterização da epiderme foi realizada de acordo com a quantificação dos parâmetros de espessura em micrômetros e número de halos perinucleares, os quais estes últimos são indicativos de início do apoptose celular (Queiroz Neta et al., 2018). Já a caracterização da derme foi realizada de acordo com a quantificação dos parâmetros de espessura em micrômetros e número de fibroblastos (Sharma et al., 2018). Adicionalmente, a espessura total das camadas da pele foi mensurada em micrômetros. Sob microscopia de luz em objetiva de 40x, foram obtidas 20 imagens aleatórias para cada grupo/animal e analisadas quantitativamente utilizando o software Image J versão 1.49. Comparações foram realizadas entre fragmentos não refrigerados e refrigerados; vitrificados e refrigerados seguidos da vitrificação.

Finalmente, para a análise estatística, os dados foram expressos como média \pm desvio padrão e analisados usando o programa GraphPad Prism a uma significância de $P<0,05$. Todos os dados foram submetidos ao teste de normalidade. Não passando pelo teste de normalidade, os valores não foram transformados e foi aplicado o teste não paramétrico de Kruskal-Wallis associado com teste de Dunn (múltiplas comparações).

\section{RESULTADOS E DISCUSSÕES}

\subsection{Influência da refrigeração na conservação de tecidos somáticos}

As características morfológicas das camadas da pele derivada de catetos não criopreservada (controle) e refrigerada a $5^{\circ} \mathrm{C}$ por $24 \mathrm{~h}$ (R-24) e $48 \mathrm{~h}$ (R-48) são mostradas na Figura 1. Inicialmente, quando apenas a refrigeração a $5^{\circ} \mathrm{C}$ foi avaliada na conservação de tecidos somáticos, nós observamos que o período de $48 \mathrm{~h}$ (R-48) afetou todos os parâmetros histológicos analisados, exceto a espessura da epiderme, a qual se manteve similar ao grupo de amostras não refrigeradas (Tabela 1). Esse resultado pode ser explicado pelas características que a epiderme possui, a qual é de origem ectodérmica e avascular, apresentando diferentes camadas, sendo estas, a camada basal, espinhosa, granulosa, lúcida e córnea bem queratinizada (Hib, 2003). Assim, essa arquitetura pode ter contribuído para que a espessura da epiderme não sofresse modificações quando submetida a refrigeração, uma vez que esta funciona como barreira de proteção. 
Enquanto a derme, de origem mesodérmica e ricamente vascularizada, é a principal responsável pela maior parte da espessura da pele (Summerfield et al., 2015), na qual tem apresentando em nossos resultados uma retração em sua espessura quando submetida a refrigeração. Adicionalmente, ambas as camadas da pele (epiderme e derme) possuem diferenças, quanto ao tipo de células na qual apresentam especificidades diferentes, quantidade de matriz extracelular que estar relacionada com o suporte e auxílio estrutural destas camadas, e a presença do suprimento vascular, no qual proporciona uma oxigenação e nutrição das células, garantindo assim a sua manutenção, são fatores que podem justificar a ausência de efeitos negativos do período de $48 \mathrm{~h}(\mathrm{R}-48)$ sobre a espessura da epiderme.

Por outro lado, ambos os períodos de refrigeração causaram uma redução da espessura da derme e da pele total de catetos. Em pele humana, Sterne et al. (2000) demostraram que a conservação a $4^{\circ} \mathrm{C}$ resultou na perda de substância celular e, consequentemente, na redução da espessura da pele, ocasionado pela redução do fornecimento sanguíneo, nutrição ineficiente e baixa funcionalidade celular.

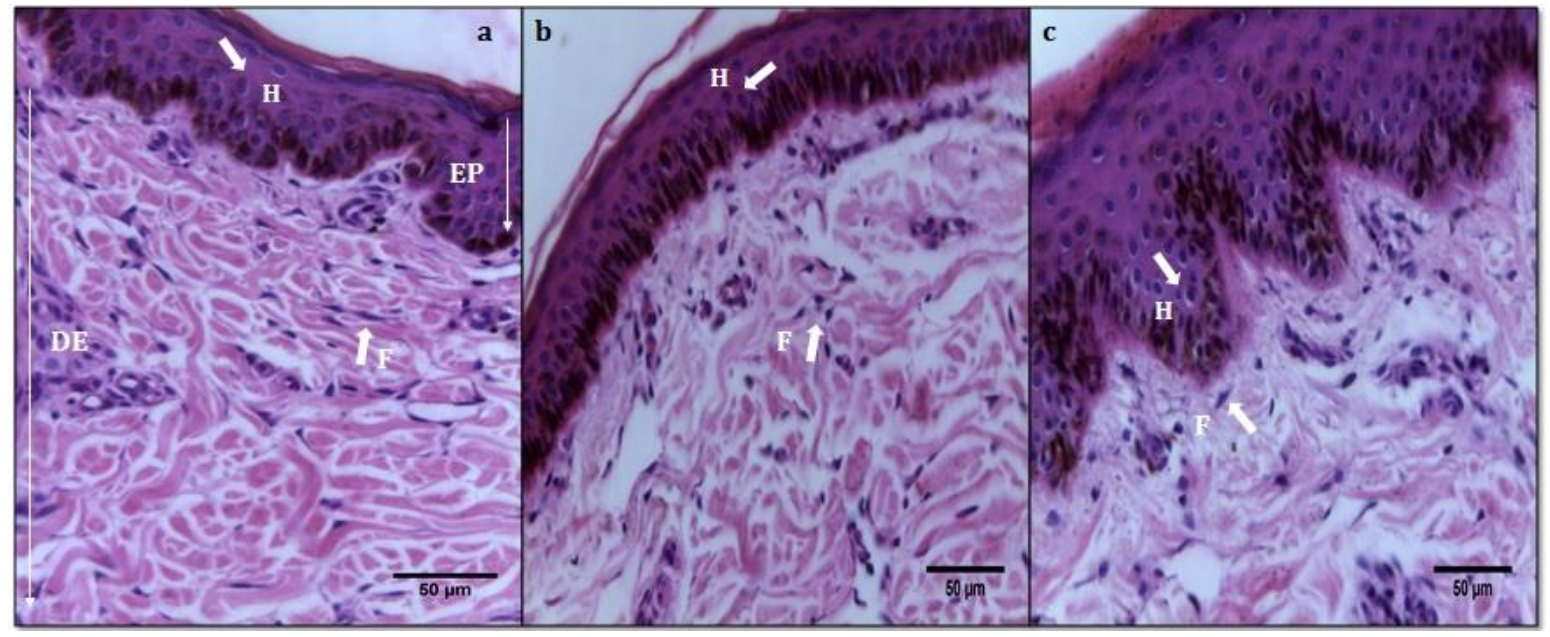

Figura 1: Análise histológica dos tecidos somáticos de catetos corados com hematoxilina-eosina. (a) Fragmentos não refrigerados. (b) Fragmentos refrigerados a $5^{\circ} \mathrm{C}$ por $24 \mathrm{~h}$. (c) Fragmentos refrigerados a $5^{\circ} \mathrm{C}$ por $48 \mathrm{~h}$. (EP) epiderme; (DE) derme; (F) fibroblastos dérmicos e $(\mathrm{H})$ halos perinucleares.

Além disso, enquanto uma redução de fibroblastos dérmicos foi apenas evidenciada no grupo de fragmentos refrigerados por $48 \mathrm{~h}$ (R-48), o aumento de halos perinucleares da epiderme foi observado em todos os grupos refrigerados, sendo acentuado nos fragmentos refrigerados por $48 \mathrm{~h}$ (R-48) (Tabela 1). Assim, o presente estudo demonstrou que a refrigeração a $5^{\circ} \mathrm{C}$ por 24 h ( $\mathrm{R}$ 24) conservou de maneira eficiente os fibroblastos dérmicos. Contudo, quando a refrigeração foi realizada por 48 h (R-48) ocorreu uma redução do número de fibroblastos. Tal afirmativa pode ser justificada porque a ausência de oxigênio por tempo prolongado ( $>24 \mathrm{~h}$ ) promoveu um aumento na morte das células (Singh e Ma, 2014). 
Tabela 1: Influência da refrigeração a $5^{\circ} \mathrm{C}$ por $24 \mathrm{~h}$ e $48 \mathrm{~h}$ na conservação de fragmentos teciduais de catetos.

\begin{tabular}{cccccc}
\hline \multirow{2}{*}{ Grupos } & \multicolumn{3}{c}{ Espessura $(\boldsymbol{\mu m})$} & \multirow{2}{*}{$\begin{array}{c}\text { No. } \\
\text { fibroblastos }\end{array}$} & $\begin{array}{c}\text { No. } \\
\text { halos }\end{array}$ \\
\cline { 2 - 4 } & Epiderme & Derme & Pele total & \\
\hline Controle & $170,6 \pm 76,5^{\mathrm{a}}$ & $453,6 \pm 60,2^{\mathrm{a}}$ & $624,2 \pm 99,2^{\mathrm{a}}$ & $36,6 \pm 12,7^{\mathrm{a}}$ & $26,6 \pm 16,8^{\mathrm{a}}$ \\
R-24 & $144,4 \pm 35,2^{\mathrm{b}}$ & $435,1 \pm 63,5^{\mathrm{b}}$ & $579,5 \pm 76,9^{\mathrm{b}}$ & $36,9 \pm 8,2^{\mathrm{a}}$ & $37,3 \pm 19,5^{\mathrm{b}}$ \\
R-48 & $167,2 \pm 62,0^{\mathrm{a}}$ & $415,5 \pm 78,2^{\mathrm{b}}$ & $582,7 \pm 76,0^{\mathrm{b}}$ & $28,3 \pm 8,1^{\mathrm{b}}$ & $54,4 \pm 20,3^{\mathrm{c}}$ \\
\hline
\end{tabular}

Média \pm desvio padrão; ${ }^{a, b, c}:$ diferem na mesma coluna (Teste de Kruskal-Wallis e teste Dunn, $\mathrm{P}<0,05$ ).

A presença de halos perinucleares da epiderme foi evidenciada em todos os fragmentos refrigerados, sendo seu quantitativo acentuado quando a refrigeração foi de 48 h (R-48) (Tabela 1). Sterne et al. (2000) afirmaram que a refrigeração causa na pele humana não somente a formação de halos, mas também de lesões nucleares e formação de vacúolos. A formação de halos, segundo Boekema et al. (2015), seriam sinais da redução da viabilidade teciduais, uma vez que esses halos indicam início do processo de morte das células.

Queiroz Neta et al. (2018), trabalhando também com refrigeração de tecidos somáticos de catetos na ausência de meio por 10, 30 e 50 dias, também evidenciaram a formação de halos em valores superiores a 50 halos em tecidos refrigerados por 10 dias. No presente estudo, nós observamos valores similares apenas na conservação a $5^{\circ} \mathrm{C}$ por $48 \mathrm{~h}(\mathrm{R}-48)$, evidenciando que já no segundo dia de conservação, a formação de halos ocorre. Embora a refrigeração possa causar efeitos deletérios sobre as amostras somáticas, é sabido que seu papel é importante na conservação de amostras somáticas de indivíduos localizados em regiões de difícil acesso ou distante de laboratórios especializados (Tovar et al., 2008). Desta maneira, conhecer as condições adequadas de estocagem promovem seu uso de modo eficiente, como observado em algumas espécies, como bovinos (Silvestre et al., 2004), mamíferos silvestres do Chile (Tovar et al., 2008), e ovinos (Singh et al., 2011).

Adicionalmente, Walcott e Singh (2017) demostraram a influência positiva da refrigeração de tecido somático, podendo prolongar o tempo de recuperação das amostras somáticas após a morte do animal. Nesse estudo, os autores observaram que células de tecidos somáticos bovinos com características morfológicas e cromossômicas estáveis puderam ser recuperadas até cerca de semanas de tecidos armazenados a $25^{\circ} \mathrm{C}$ e por até seis semanas de tecidos refrigerados a $4^{\circ} \mathrm{C}$.

3.2 Influência da refrigeração sobre a vitrificação de tecidos somático 
As características morfológicas das camadas da pele derivada de catetos não refrigerada e vitrificada (vitrificação), refrigerada a $5^{\circ} \mathrm{C}$ por $24 \mathrm{~h}$ e vitrificada (RV-24) e refrigerada a $5^{\circ} \mathrm{C}$ por $48 \mathrm{~h}$ e vitrificada (RV-48) são mostradas na Figura 2.

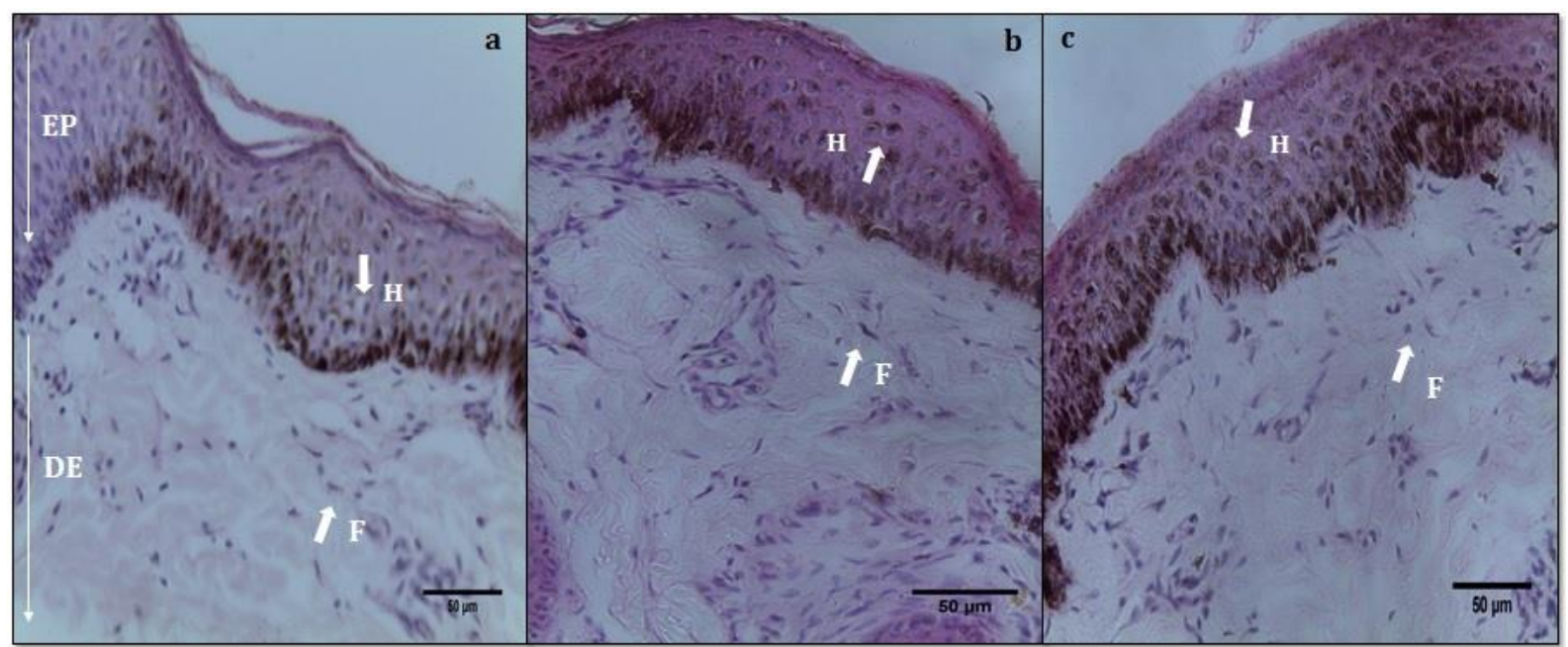

Figura 2: Análise histológica dos tecidos somáticos de catetos corados com hematoxilina-eosina. (a) Fragmentos não refrigerados e vitrificados. (b) Fragmentos refrigerados por $24 \mathrm{~h}$ e vitrificados. (c) Fragmentos refrigerados por $48 \mathrm{~h}$ e vitrificados. (EP) epiderme; (DE) derme; (F) fibroblastos e (H) halos perinucleares.

Na segunda etapa, tanto a espessura da epiderme, quanto da derme e pele total foram afetadas pela vitrificação após a refrigeração por 48 h (RV-48) $(P<0,05$, Tabela 2). Assim, a refrigeração seguida da vitrificação por 24 h (RV-24) afetou somente o número de halos perinucleares, enquanto a refrigeração por 48 h (RV- 48) afetou a qualidade dos tecidos somáticos de catetos em todos os parâmetros avaliados. Ainda quando avaliamos a influência da refrigeração a $5^{\circ} \mathrm{C}$ sobre a vitrificação de tecidos somáticos de catetos, observamos que somente a refrigeração por 48 h (RV-48) afetou todos os parâmetros de qualidade dos tecidos vitrificados. Tal afirmativa pode ser explicada porque os efeitos deletérios da refrigeração por $48 \mathrm{~h}$ (RV-48) foram somados aos efeitos deletérios dos crioprotetores e do procedimento de vitrificação (Erdag et al., 2002).

Além disso, enquanto uma redução de fibroblastos dérmicos foi apenas evidenciada no grupo RV-48, o aumento de halos perinucleares da epiderme foi observado em todos os grupos vitrificados, sendo acentuado nos fragmentos refrigerados por $48 \mathrm{~h}$ e vitrificados (RV-48) (Tabela 2). De acordo com Silvestre et al. (2004), isso pode ser justificado devido a uma interação entre a temperatura de armazenamento e o tratamento da amostra, vitrificação, neste caso, uma vez que amostras armazenadas a $4^{\circ} \mathrm{C}$ obtiveram um declínio acentuado na sobrevivência celular em comparação com amostras armazenadas em temperaturas a $22-25^{\circ} \mathrm{C}$. Assim, a queda na viabilidade tecidual pode ser acompanhada pelo surgimento de células apoptóticas, resultando em células perinucleares ou halos (Boekema et al., 2015). 
Tabela 2: Influência da conservação a $5^{\circ} \mathrm{C}$ por $24 \mathrm{~h}$ e $48 \mathrm{~h}$ sobre a vitrificação de fragmentos teciduais de catetos.

\begin{tabular}{cccccc}
\hline \multirow{2}{*}{ Grupos } & \multicolumn{3}{c}{ Espessura $(\mu \mathrm{m})$} & \multirow{2}{*}{$\begin{array}{c}\text { No. } \\
\text { fibroblastos }\end{array}$} & $\begin{array}{c}\text { No. } \\
\text { halos }\end{array}$ \\
\cline { 2 - 4 } & Epiderme & Derme & Pele Total & & \\
\hline V & $130,5 \pm 32,6^{\mathrm{a}}$ & $416,9 \pm 74,0^{\mathrm{a}}$ & $547,4 \pm 68,3^{\mathrm{a}}$ & $40,1 \pm 8,7^{\mathrm{a}}$ & $21,5 \pm 20,6^{\mathrm{a}}$ \\
RV-24 & $127,3 \pm 36,4^{\mathrm{a}}$ & $433,1 \pm 66,0^{\mathrm{a}}$ & $560,5 \pm 68,3^{\mathrm{a}}$ & $38,0 \pm 8,6^{\mathrm{a}}$ & $34,4 \pm 19,3^{\mathrm{b}}$ \\
RV-48 & $160,9 \pm 46,3^{\mathrm{b}}$ & $446,7 \pm 59,1^{\mathrm{b}}$ & $607,6 \pm 57,1^{\mathrm{b}}$ & $31,6 \pm 9,0^{\mathrm{b}}$ & $50,6 \pm 16,1^{\mathrm{c}}$ \\
\hline
\end{tabular}

Média \pm desvio padrão; ${ }^{b, c}$ : diferem na mesma coluna $(P<0,05) . V=$ fragmentos vitrificados e não refrigerados.

Os crioprotetores possibilitam que a funcionalidade celular seja recuperada após o armazenamento prolongado em baixas temperaturas (Elliott et al., 2017). Contudo, a toxicidade desses agentes é um dos principais fatores que pode vir a interferir na criopreservação de tecidos (Lewis et al., 2016). O estresse osmótico está diretamente relacionado com a criopreservação de tecidos e seu excesso pode vir a afetar a estrutura proteica, reduzir a atividade enzimática, causando danos no DNA e morte celular por apoptose (Best, 2015).

Adicionalmente, o contato direto dos crioprotetores com a membrana das células é responsável pelo surgimento de danos celulares, de modo a ocasionar uma permeabilização (Ménorval et al., 2012), ou desidratação osmótica (Simonin et al., 2007). A membrana celular apresenta uma ótima capacidade de absorção a água quando comparada aos crioprotetores. Assim, a exposição das células aos crioprotetores dá início um processo de desidratação, bem como a captação de agentes crioprotetores e água. Em seguida, a célula induz as suas condições isotônicas e caso ocorra o excesso de tolerância osmótica na célula, pode ocorrer a saída de solutos intracelulares e danos irreversíveis associados a desidratações graves (Sydykov et al., 2018).

Contudo, estudos que abordem o conhecimento a respeito das condições de conservação de tecidos que antecedem o tratamento de criopreservação, de modo a proporcionar as características celular e tecidual normais, ainda são escassos (Silvestre et al., 2004). Em 2003, Silvestre et al., avaliaram os efeitos do armazenamento $\left(4^{\circ} \mathrm{C}, 22-25\right.$ e $\left.35^{\circ} \mathrm{C}\right)$ por 240,72 e $24 \mathrm{~h}$ postmortem seguidos da vitrificação de tecido da pele de leporinos e suínos, onde observou-se a capacidade de proliferação após o aquecimento. Os dados demostraram que a vitrificação foi positiva na conservação, visto que em suínos em todos os parâmetros testados obteve-se sobrevivência após o aquecimento da vitrificação, enquanto em leporinos apenas os fragmentos armazenados a $35^{\circ} \mathrm{C}$ durante $24 \mathrm{~h}$ não apresentaram sobrevivência. Já em 2004, Silvestre et al., avaliaram por meio do cultivo in vitro o efeito da vitrificação sobre o armazenamento em diferentes temperaturas e tempo após óbito do animal $\left(4^{\circ} \mathrm{C}-12,252\right.$ e $348 \mathrm{~h} ; 22$ a $25^{\circ} \mathrm{C}-60$ e $\left.90 \mathrm{~h}\right)$ em tecido da pele de bovinos, caprinos e ovinos. No entanto, foi evidenciado diferenças entre os grupos não vitrificados e vitrificados quando a pele foi armazenada a $4^{\circ} \mathrm{C}$ por 12 e $252 \mathrm{~h}$. Além disso, os fragmentos teciduais armazenados a $4{ }^{\circ} \mathrm{C}$ apresentaram maior tempo para atingir a subconfluência quando comparada as amostras armazenadas a $22-25^{\circ} \mathrm{C}$. Assim, a vitrificação é eficiente e válida para a conservação do material genético destas espécies. 
Portanto, o estabelecimento das condições de refrigeração a $5^{\circ} \mathrm{C}$ é interessante, pois permite a conservação de amostras somáticas de espécies silvestres ameaças ou não de extinção, e que tais condições visam manter a viabilidade do material biológico de interesse. Além disso, é importante ressaltar que o intuito deste estudo foi avaliar condições de armazenamento, visando estabelecer metodologias simples e de baixo custo, considerando situações adversas de localização desses animais.

\section{CONCLUSÃO}

Independente do período de armazenamento, $24 \mathrm{~h}$ ou $48 \mathrm{~h}$, a refrigeração a $5^{\circ} \mathrm{C}$ na ausência de meio nutritivo afetou a qualidade dos tecidos somáticos de catetos, sendo esses efeitos acentuados quando os fragmentos foram refrigerados por $48 \mathrm{~h}$ e vitrificados. Portanto, sugere-se, quando necessário, o período de $24 \mathrm{~h}$ de refrigeração na ausência de meio nutritivo para amostras somáticas derivadas de catetos que irão ainda ser vitrificadas.

\section{REFERÊNCIAS BIBLIOGRÁFICAS}

Best, B. P. (2015). Cryoprotectant toxicity: facts, issues, and questions. Rejuvenation Research, 18, $422-436$.

Boekema, B. K. H. L., Boekestijn, B., Breederveld, R. S. (2015). Evaluation of saline, RPMI and DMEM/F12 for storage of split-thickness skin grafts. Burns, 41, 848-852.

Borges, A. A., Lima, G. L., Queiroz Neta, L. B., Santos, M. V. O., Oliveira, M. F., Silva, A. R., \& Pereira, A. F. (2017). Conservation of somatic tissue derived from collared peccaries (Pecari tajacu Linnaeus, 1758) using direct or solid-surface vitrification techniques. Cytotechnology, 69, 643654.

Borges, A. A., Lira, G. P. O., Nascimento, L. E., Queiroz Neta, L. B., Santos, M. V. O., Oliveira, M. F., Silva, A. R., \& Pereira, A. F. (2018). Influence of cryopreservation solution on the in vitro culture of skin tissues derived from collared peccary (Pecari tajacu Linnaeus, 1758). Biopreservation and Biobanking, 16, 77-81.

Caamaño, J. N., Rodriguez, A., Muñoz, M., Frutos, C., Diez, C., \& Gómez, E. (2008). Cryopreservation of brown bear skin biopsies. Cell Preservation Technology, 6, 83-86.

Desbiez, A. L. J., Keuroghlian, A., Beisiegel, B. M., Medici, E. P., Gatti, A., Pontes, A. R. M., Campos, C. B., Tófoli, C. F., Júnior, E. A. M., Azevedo, F. C., Pinho, G. M., Cordeiro, J. L. P., Morais, A. A., Mangini, P. R., Flesher, K., Rodrigues, L. F., \& Almeida, L. B. (2012). Avaliação do risco de extinção do cateto Pecari tajacu Linnaeus, 1758, no Brasil. Biodiversidade Brasileira, 1, 74-83. 
Elliott, G. D., Wang, S., \& Fuller, B. J. (2017). Cryoprotectants: A review of the actions and applications of cryoprotective solutes that modulate cell recovery from ultra-low temperatures. Cryobiology, 76, 74-91.

Erdag, G., Eroglu, A., Morgan, J. R., \& Toner, M. (2002). Cryopreservation of fetal skin is improved by extracellular trehalose. Cryobiology, 44, 218-228.

Hib, J. (2003). Sistema tegumentar, p.215-233. In: Hib J. (Ed.), Di Fiori Histologia. Guanabara Koogan, Rio de Janeiro.

IUCN, IUCN Red List of Threatened Species. Ano de publicação 2015. Disponível em: http://www.iucnredlist.org/details/4015/0. Acesso em 17 de fevereiro de 2020.

Lewis, J. K., Bischof, J. C., Braslavsky, I., Brockbank, K. G., Fahy, G. M., Fuller, B. J., Rabin, Y., Tocchio, A., Woods, E. J., Wowk, B. G., Acker, J. P., \& Giwa, S. (2016). The grand challenges of organ banking: proceedings from the first global summit on complex tissue cryopreservation. Cryobiology, 72, 169-182.

Lima, G. L., Santos, E. A. A., Lima, L. F., Luz, V. B., Rodrigues, A. P. R., \& Silva, A. R. (2014). Short-term preservation of Pecari tajacu ovarian preantral follicles using phosphate buffered saline (PBS) or powdered coconut water $\left(\mathrm{ACP}^{\circledR}\right)$ media. Arquivo Brasileiro de Medicina Veterinária e Zootecnia, 66, 1623-1630.

Mayor, P., Guimarães, D., Le Pendu, Y., Silva, J. V., Jori, F., \& López-Béjar, M. (2007). Reproductive performance of captive collared peccaries (Tayassu tajacu) in the eastern Amazon. Animal Reproduction Science, 102, 88-97.

Ménorval, M. A., Mir, L. M., Fernández, M. L., \& Reigada, R. (2012). Effects of dimethyl sulfoxide in cholesterol-containing lipid membranes: a comparative study of experiments in silico and with cells. PloS one, 7, p. e41733.

Minervino, A. H. H., Araújo, C. A. S. C., Barrêto-Júnior, R. A., Soares, H. S., Oliveira, M. F., Mori, C. S., Neves, K. A. L., Vale, W. G., Gennari, S. M., \& Ortolani, E. L. (2014). Serum biochemistry of collared peccaries (Pecari tajacu) in captivity in Northeastern Brazil. Pakistan Veterinary Journal, 34, 538-540.

Okonkwo, C., \& Singh, M. (2014). Recovery of fibroblast-like cells from refrigerated goat skin up to $41 \mathrm{~d}$ of animal death. In Vitro Cell Development and Biology Animal, 51, 463-469.

Pereira, A. F., Borges, A. A., Santos, M. V. O., \& Lira, G. P. O. (2019). Use of cloning by nuclear transfer in the conservation and multiplication of wild mammals. Revista Brasileira de Reprodução Animal, 43, 242-247.

Queiroz Neta, L. B., Lira, G. P. O., Borges, A. A., Santos, M. V. O., Silva, M. B., Oliveira, L. R. M., Silva, A. R., Oliveira, M. F., \& Pereira, A. F. (2018). Influence of storage time and nutrient medium on recovery of fibroblast-like cells from refrigerated collared peccary (Pecari tajacu Linnaeus, 1758) skin. In Vitro Cellular \& Developmental Biology-Animal, 54, 486-495. 
Sharma, R., Sharma, H., Ahlawat, S., Aggarwal, R. A. K., Vij, P. K., \& Tantia, M. S. (2018). First attempt on somatic cell cryopreservation of critically endangered Camelus bactrianus of India. Gene Reports, 10, 109-115.

Silva, A. M., Bezerra, L. G. P., Praxedes, E. C. G., Moreira, S. S. J., Souza, C. M. P., Oliveira, M. F., Pereira, A. F., Comizzoli, P., \& Silva A. R. (2019). Combination of intracellular cryoprotectants preserves the structure and the cells proliferative capacity potential of adult collared peccary testicular tissue subjected to solid surface vitrification. Cryobiology, 91, 53-60.

Silvestre, M. A., Saeed, A. M., Escriba, M. J., \& Garcia-Ximénez, F. (2002). Vitrification and rapid freezing of rabbit fetal tissues and skin samples from rabbits and pigs. Theriogenology, 58, 6976.

Silvestre, M. A., Saeed, A. M., Cervera, R. P., Escribá, M. J., \& García-Ximénez, F. (2003). Rabbit and pig ear skin sample cryobanking: effects of storage time and temperature of the whole ear extirpated immediately after death. Theriogenology, 46, 1469-1477.

Silvestre, M. A., Sánchez, J. P., \& Gómez, E. A. (2004). Vitrification of goat, sheep, and cattle skin samples from whole ear extirpated after death and maintained at different storage times and temperatures. Theriogenology, 49, 221-229.

Simonin, H., Beney, L., \& Gervais, P. (2007). Sequence of occurring damages in yeast plasma membrane during dehydration and rehydration: mechanisms of cell death. Biochimica et Biophysica Acta (BBA)-Biomembranes, 1768, 1600-1610.

Singh, M., Ma, X., Amoah, E., \& Kannan, G. (2011). In vitro culture of fibroblast-like cells from postmortem skin of Katahdin sheep stored at $4^{\circ} \mathrm{C}$ for different time intervals. In Vitro Cellular \& Developmental Biology - Animal, 47, 290-293.

Singh, M., \& Ma, X. (2014). In vitro culture of fibroblast-like cells from sheep ear skin stored at 25$26^{\circ} \mathrm{C}$ for 10 days after animal death. International Journal of Biology, 6, 96-102.

Sydykov, B., Oldenhof, H., Barros, L. O., Sieme, H.; \& Wolkers, W. F. (2018). Membrane permeabilization of phosphatidylcholine liposomes induced by cryopreservation and vitrification solutions. Biochimica et Biophysica Acta (BBA)-Biomembranes, 1860, 467-474.

Sterne, G. D., Titley, O., \& Christie, J. L. (2000). A qualitative histological assessment of various storage conditions on short term preservation of human split skin grafts. British Journal of Plastic Surgery, 53, 331-336.

Summerfield, A., Meurens, F., \& Ricklin, M. E. (2015). The immunology of the porcine skin and its value as a model for human skin. Molecular Immunology, 66, 14-21.

Tovar, H., Navarrete, F., Rodríguez, L., Skewes, O., \& Castro, F. O. (2008). Cold storage of biopsies from wild endangered native Chilean species in field conditions and subsequent isolation of primary culture cell lines. In Vitro Cellular \& Developmental Biology-Animal, 44, 309-320. 
Walcott, B, \& Singh, M. (2017). Recovery of proliferative cells up to 15-and 49-day postmortem from bovine skin stored at $25^{\circ} \mathrm{C}$ and $4^{\circ} \mathrm{C}$, respectively. Cogent Biology, 3, 1333760 .

\section{COMO CITAR ESTE ARTIGO:}

Silva, M. B., Queiroz Neta, L. B. de, Oliveira, L. R. M. de, Nascimento, M. B. do, Aquino, L. V. C. de, Borges, A. A., Santos, M. V. de O., Pereira, A. F. (2020). Conservação de tecidos somáticos de catetos (pecari tajacu linnaeus, 1758) submetido a diferentes condições de armazenamento. Holos. 36(7), 1-14.

\section{SOBRE OS AUTORES}

\section{B. Silva}

Bacharel em Biotecnologia pela Universidade Federal Rural do Semi-Árido (UFERSA)(2013-2018), Atualmente, mestranda do Programa de Pós-Graduação em Ciência Animal, da UFERSA, sob a orientação da Profa. Dra. Alexsandra Fernandes Pereira, com atuação na área de Ciências Agrárias, com ênfase em Morfofisiologia e Biotecnologia Animal. UFERSA. Membro do Laboratório de Biotecnologia Animal (LBA) sob a orientação da Profa. Dra. Alexsandra Fernandes Pereira. E-mail: brbarasilva46@yahoo.com ORCID ID: http://orcid.org/0000-0001-5745-3279

\section{B. de Queiroz Neta}

Luiza Bento de Queiroz Neta possui graduação em Biotecnologia pela Universidade Federal Rural do SemiÁrido (2011- 2015). Foi aluna de iniciação científica da Universidade Federal Rural do Semi-Árido no Laboratório de Biotecnologia Animal (UFERSA/LBA), sob a orientação da Profa. Dra. Alexsandra Fernandes Pereira. Possui mestrado em Ciência Animal (2016-2017) pela Universidade Federal Rural do Semi-Árido (UFERSA). Tem experiência na área de Biotecnologia com ênfase em biotécnicas aplicadas à conservação e reprodução animal (cultivo celular, partenogênese, fecundação in vitro e transferência nuclear de células somáticas). E-mail: luizabentoqueiroz@gmail.com

ORCID ID: http://orcid.org/0000-0001-9267-6988

\section{R. M. de Oliveira}

Bacharela em Biotecnologia pela Universidade Federal Rural do Semi-Árido - UFERSA. Atual mestranda do Programa de Pós-Graduação em Ciência Animal (CAPES) pela Universidade Federal Rural do Semi-Árido. Atuando no Laboratório de Biotecnologia Animal (UFERSA/LBA), sob a orientação da Profa. Dra. Alexsandra Fernandes Pereira, desenvolvendo atividades de análise de qualidade oocitária, maturaçao in vitro de oócitos, produção in vitro de embriões, cultivo in vitro de células somáticas, conservação de animais silvestres, criopreservação e análises celulares. E-mail: lharagirs@ hotmail.com ORCID ID: http://orcid.org/0000-0002-7292-6908

\section{B. do Nascimento}

ossui graduação no curso Bacharel de Biotecnologia pela Universidade Federal Rural do Semi-Árido (20162019). Durante a graduação, foi aluno bolsista no programa de Iniciação Científica Institucional. Atualmente, é aluno mestrando do Programa de Pós-Graduação em Ciência Animal (PPGCA/UFERSA). Além disso, é integrante do Laboratório de Biotecnologia Animal (LBA/UFERSA), onde desenvolve pesquisas na área de Morfofisiologia e Biotecnologia Animal aplicadas à conservação de espécies silvestres (Histologia, Cultivo in vitro e Produção in vitro de embriões) sob orientação da Profa. Dra. Alexsandra Fernandes Pereira. E-mail: matheus_mbn@hotmail.com

ORCID ID: http://orcid.org/0000-0003-2661-0846

\section{V. C. de Aquino}


Leonardo Vitorino Costa de Aquino possui graduação no curso Bacharel de Biotecnologia pela Universidade Federal Rural do Semi-Árido (2016-2019). Durante a graduação, foi aluno bolsista no programa de Iniciação Científica Institucional (PICI/UFERSA, 2018-2019). Atualmente, é aluno mestrando do Programa de PósGraduação em Ciência Animal (PPGCA/UFERSA). Além disso, é integrante do Laboratório de Biotecnologia Animal (LBA/UFERSA), onde desenvolve pesquisas na área de Morfofisiologia e Biotecnologia Animal aplicadas à conservação de espécies silvestres (Histologia, Cultivo in vitro e Produção in vitro de embriões) sob orientação da Profa. Dra. Alexsandra Fernandes Pereira. E-mail: leonardovt@live.com ORCID ID: http://orcid.org/0000-0001-7192-7581

\section{A. A. Borges}

Alana Azevedo Borges possui graduação em Biotecnologia pela Universidade Federal Rural do Semi-Árido (2010 - 2015) com período sanduíche (2012 - 2013) pelo Programa Ciências sem Fronteiras em Biotecnología pela Universitat de Lleida, Espanha. Licenciatura em Biologia pelo Centro Universitário Claretiano (2016 2018). Possui mestrado em Ciência Animal (2015-2016) pela Universidade Federal Rural do Semi-Árido (UFERSA). Atualmente, está concluindo seu doutorado pelo Programa de Pós-Graduação em Ciência Animal na UFERSA. É integrante do Laboratório de Biotecnologia Animal (LBA/UFERSA) onde desenvolve pesquisas com ênfase em morfofisiologia, biotécnicas aplicadas à conservação e reprodução animal (histologia, desenvolvimento embrionário, avaliação do ciclo celular, cultivo in vitro,criopreservação, partenogênese, fecundação in vitro e transferência nuclear de células somáticas) sob a orientação da Profa. Dra. Alexsandra Fernandes Pereira. E-mail: alanaazevedob@gmail.com

ORCID ID: http://orcid.org/0000-0002-7118-261X

\section{V. de O. Santos}

Maria Valéria de Oliveira Santos é graduada em Biotecnologia pela Universidade Federal Rural do Semi-árido (UFERSA), possui mestrado em Ciência Animal (2016-2018) pela UFERSA e, atualmente, é doutoranda do Programa de Pós-Graduação em Ciência Animal (PPGCA). Como integrante do Laboratório de Biotecnologia Animal (LBA/UFERSA), desenvolve estudos com ênfase na produção in vitro de embriões em mamíferos domésticos e biotécnicas aplicadas à conservação animal, sob a orientação da Profa. Dra. Alexsandra Fernandes Pereira. E-mail: valeriasnts07@gmail.com

ORCID ID: http://orcid.org/0000-0002-4293-507X

\section{A. F. Pereira}

Alexsandra Fernandes Pereira possui graduação em Química pela Universidade Estadual do Ceará (20012004), mestrado (2005-2006) e doutorado em Ciências Veterinárias (2007-2010) na mesma instituição, com estágio doutorado-sanduíche pela Universidade de Buenos Aires, Argentina. Possui pós-doutorado em transgênese animal através do Programa Nacional de Pós-Doutorado (PNPD) do CNPq (2011-2013). Desde 2013, é professora do curso de graduação em Biotecnologia e do Programa de Pós-Graduação em Ciência Animal (PPCA), do Departamento de Ciências Animais (DCAN), da Universidade Federal Rural do Semi-Árido (UFERSA), ministrando as disciplinas de Histologia e Embriologia Animal, Cultura Celular Básica, Biotecnologia Animal e Técnicas avançadas de manipulação embrionária. Atualmente, é professora Adjunta C, nível 1, orientadora de doutorado, mestrado e iniciação científica. Responsável técnica do Laboratório de Biotecnologia Animal (LBA/UFERSA) onde desenvolve pesquisas com ênfase em biotécnicas aplicadas à conservação e reprodução animal (cultivo celular, partenogênese, fecundação in vitro e transferência nuclear de células somáticas).E-mail: ale_lfcr@yahoo.com.br

ORCID ID: http://orcid.org/0000-0003-2137-854X

Editor(a) Responsável: Francinaide de Lima Silva Nascimento

Pareceristas Ad Hoc: DANIELLE PAES-BRANCO E FELIPE DOS SANTOS 


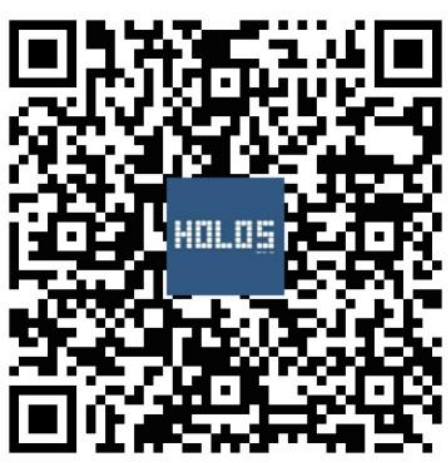

